\title{
WAYS OF CONFRONTING CORRUPTION AND BRIBERY IN THE BODIES OF THE STATE AUTHORITY
}

\author{
Volodymyr Yemelyanov' ${ }^{1}$ Dmytro Plekhanov ${ }^{2}$
}

\begin{abstract}
The article outlines the problems of corruption and bribery in public authorities in Ukraine. The destructive influence of corruption provokes and deepens the social crisis, undermines the image of the Civil Service of Ukraine, and holds back the socio-economic development of the country. Currently, corruption in Ukraine is called one of the most significant threats to national security. The aim of this article is to substantiate main directions and means of confronting corruption and bribery in the system of state authorities in Ukraine. The object of the research is the social relations that arise in the process of counteracting corruption and bribery. The methodology of the research is based on the fundamental provisions of the public administration theory, as well as on the concepts developed both by the Ukrainian and foreign researchers and practitioners aimed at preventing and counteracting corruption. Main theoretical provisions and conclusions of the article highlight effective measures of preventing and counteracting corruption in state authorities in Ukraine. The results of the research can be useful for the public administration bodies when developing and implementing anti-corruption programs or laws and regulations on the issues of forming an anticorruption consciousness of citizens and state authority officials. Value/originality. The article outlines the economic-mathematical model of "bribe maximization", which takes into account the limitations of the possibility of offering and agreeing to receive a bribe. The model is the basis, which proves that the most effective way of fighting corruption is streamlining the efforts of the authorities on creating a competitive environment: "economic benefit - the risk of punishment". These conditions decrease the officials' interest to receive bribes since their size ceases to compensate for the risk of disclosure, detention, and punishment. Meanwhile, the series of other practices are also important, namely: building a holistic legal system based on integrity; introduction of mechanisms of accountability and responsibility of officials; cooperation with civil society and the private sector; adaptation of international experience to national realities; identification of "high risk zones" for diverting there main efforts and resources.
\end{abstract}

Key words: bribery, corruption, manifestations of corruption, counteraction to corruption, responsibility, civil servants, state authorities.

JEL Classification: E61, Z18

\section{Introduction}

Corruption as a social phenomenon has emerged a long time ago. It may seem that the birth of corruption was probably either simultaneous with the birth of the human race or happened at least right with the emergence of power and financial relations. Today, some studies consider corruption as a necessary tool for "wheel lubrication". From this perspective, corruption helps to overcome excessive bureaucratic constraints, ineffective provision of public services and tough laws, especially in the countries where there are weak and poorly functioning state institutions. On the other hand, corruption can lead to a significant reduction in economic performance. This is due to rent-seeking, increased transaction costs and uncertainty, inefficient investments and incorrect allocation of production factors (Hanousek, 2015).

The importance of studying corruption in the government bodies is necessitated by the vast amount of negative consequences that it is associated with. Corruption provokes and increases social crisis and undermines the image of the civil service in Ukraine. Moreover, it hampers the development of Ukraine, adversely affects the economic processes, prevents the establishment of a constructive dialogue between the authorities and the public, and destroys the foundations of building the rule of law in the country and civil society. It also violates the principles of the rule of law, justice

\footnotetext{
Corresponding author:

${ }^{1}$ Petro Mohyla Black Sea National University, Ukraine.

E-mail: volodymyr.yemelyanov@chmnu.edu.ua

${ }^{2}$ Petro Mohyla Black Sea National University, Ukraine.

E-mail: d_idu@ukr.net
} 
and equality, responsibility for the committed acts and fair competition. Transparency International, a global anticorruption organization, identifies a very high level of corruption in Ukraine, which is the consequence of the country's overall political, social, and economic problems. Such negative phenomena are quite inherent for a country that is in a state of crisis.

According to the Corruption Perceptions Index, which has been developed by Transparency International (2016), by the corruption index Ukraine in 2016 was on the 131st place; in 2015 - 130th place; 2014 - 142nd place; 2013 and 2012 - 144th place. In 2011, the index dropped to the mark of 152 . The situation was better in 2010 - 134th place; in 2009 - 146th; in 2008 - 134th; in 2007 - 118th; in 2006 - 99th place; in 2005 - 107th place; in 2004 - 122nd place; 2003 - 106th place; 2002 - 85th place; 2001 - 83rd place; 2000 - 87th place; 1999 - 75th place; 1998 - 69th place.

Among the European countries, Ukraine has been recognized as the most corrupted state almost every year. So, the problems of preventing and counteracting corruption are among the most pressing problems for Ukraine today. The scale of its spread constitutes a real threat to national security and democratic development. The fight against corruption is in the limelight of state institutions, nongovernmental organizations, the media and common citizens. The reforms, which are currently being implemented in Ukraine (the judicial, tax, and administrative), all have an anticorruption bias. Moreover, the criminal justice reform together with the improvement of the mechanisms of public access to information and obtaining legal aid are gradually forming a national anticorruption system, which will be more efficient and of higher quality.

The need for scientific substantiation and the development of technologies for preventing and counteracting corruption in the bodies of state authorities of Ukraine stress the importance of this research. This leads to the introduction of comprehensive measures in this sphere, namely: improvement of national legislation in the context of compliance with international anticorruption standards; increase in the effectiveness of the corruption prevention and counteraction system; reduction of corruption in the system of lawenforcement bodies, other bodies of state power and local governments; reduction of the shadow economy; development of an active public consciousness for the prevention and counteraction to corruption.

\section{Literature review}

Many researchers have investigated the problem of corruption and the ways of counteracting it. The first research of corruption and the term "corruption" as a "disease" of a state organism at first appeared in the writings of N. Machiavelli, C. Montesquieu and J.-J. Rousseau (Ilienok, 2013).
So, Rose-Ackerman, considering the existence of corruption in various spheres of public life, was the first to introduce the term anticorruption institutionalism (Rose-Ackerman, 2003, p. 77). Melnyk (2004) defines the social nature of corruption, its developmental trends, and negative consequences. The author analyses the elemental content of the mechanism of corruption and characterizes corruption offenses. Alforov (2011) focuses on the mechanisms of counteraction to corruption in the internal affairs bodies. Kokhan (2013) identifies political corruption as a conflict phenomenon and examines its influence on the interaction of society and the state. Charron, Dahlström, \& Lapuente (2016) investigate corruption in the field of public service. Flejchuk (2008) points out priority areas, sectors and the goal-oriented means to reduce the shadow economy and combat corruption in the system to strengthen the economic security of Ukraine in the context of globalization. Nevmerzhytskyj (2008) sees corruption as a complex socio-political phenomenon. $\mathrm{He}$ identified the causes and conditions that feed corruption, develops mechanisms and methods of limiting its manifestations. Bratkovskyj (2010) has presented comprehensive conceptual foundations for the formation of the organizational and managerial mechanism of counteraction to corruption in Ukraine as the main factor of increasing confidence in public authority.

Despite the fact that the phenomenon of corruption has been discussed in the works of many researchers, some areas remain not completely researched, namely: the specific nature of corruption in the system of government bodies, its disorganized and reorganized influence on the society, the role of civil society in counteracting the corrupt practices. The abovementioned draws the need to develop mechanisms for finding a way out of this catastrophic situation with the help of introducing effective measures for the prevention and counteraction to corruption in state authorities.

The aim of this article is to study the main areas of fighting corruption and bribery in the system of state authorities in order to develop further constructive proposals for solving these problems in Ukraine.

\section{Method of research}

The research process has entailed the use of a set of general and special methods which resonate with the purpose of the article, namely: induction, deduction, comparison, and systematization of the preconditions for the emergence of corruption. With the help of the logical-semantic method and the method of ascending from abstract to concrete, the authors developed the conceptual apparatus; the essence of the concept "corruption" received a comprehensive description. The structural-logical and system-functional analysis 
methods helped to identify the causes of corruption in Ukraine, as well as to predict the consequences of the subsequent impact of corruption in Ukraine. The creation of the economic-mathematical model entailed usage of a systematic approach, modelling and generalization. The model takes into account the limitations on the possibility of proposing and agreeing to receive a bribe, as well as a systematization of technologies for combating corruption and bribery in the system of Ukrainian state authorities.

\section{The theoretical basis of the fight against corruption as a source of destructive power}

The modern world perceives corruption as a destructive phenomenon, which is present in many fields, including politics and public administration. It is a destabilizing factor in public life, which threatens national security and impedes the development of democracy and growth of the population's well-being. The impact of corruption on competition in commodity markets is directly related to economic security in major sectors of the economy, industry, including engineering (Bublyk et. al., 2017). A characteristic feature of corruption is the conflict between the actions of an official, the interests of the employer and the interests of society.

Currently, corruption in Ukraine can be described as a special kind of corruption - a crisis-type corruption. On the one hand, it is generated by the social crisis in Ukraine, and on the other - it is the result of the crisis and, at the same time, it forms the basis (foundation) for deepening the crisis. This kind of corruption has the ability to stop any reforms in the country. Moreover, it may cause alienation of Ukraine in the world. Effective counteraction to corruption will largely depend on how profoundly and comprehensively society will understand the philosophy of the corruption phenomenon.

Corruption is an ancient phenomenon. It manifests in all spheres of human life and depends on the level of society's culture, national mentality, legal consciousness, religious, and ethnic traditions.

Corruption as a social phenomenon emerged with the creation of power relations between humans. In the age of tribes and tribal alliances and the formation of communities/first nations, leaders needed to negotiate with other unions, solve interethnic and intertribal conflicts, engage in various management activities, which reduced their personal contribution to the economic activity of the primitive (sub-state) society. Thus, the changed form of participation in tribal life created the need for certain remuneration for the time spent on social affairs in the form of other benefits and certain results of work. As a consequence, the tribes that were a part of the union and received protection were obliged to make gifts. Also in order to avoid armed attacks and looting, neighbouring tribes tended to establish contractual relations in the form of redemption from the conquest by other tribes.

In such a way, the introduction of the tradition of "tribute - gift - bribe" arose almost with the birth of human race on Earth and acquired signs of a systemic phenomenon with the separation of functions of management in social or economic activities.

The essence of such a phenomenon as "tribute - gift bribe" is the unity of the three elements:

1) appropriate favourable reaction of the person receiving the goods;

2 ) the reward for the desirable act of the "recipient";

3) the withdrawal of income from the family/tribe/ individual.

At every evolutionary stage of society's development "a society without a state $\rightarrow$ a state-organized society", a person organized one's life in order to adapt oneself in the best possible manner to the changing conditions oflife and satisfy one's growing needs through the mechanism of redistribution of goods. Such redistribution took place in accordance with the established norms of morality and customs. With the development of the exchange, this phenomenon diverged into two components: "gift" and "tribute - bribe". The latter is now only given to persons who occupy a certain social position, which in legal science, as a rule, is called "post-government power" or in the economics - "discretionary".

It should be emphasized that at this stage, the concept "tribute - bribe" cannot be considered to be a harmful phenomenon. On the contrary, it plays a positive role since it frees persons who exercise control in a stateowned society from everyday household concerns. This is a pre-corrupt practice, which is encouraged by the norms of primitive morality.

On the one hand, the "tribute - bribe" implies the reaction of someone who is bribed in a form of a favour for a certain person. On the other - the one who gives a "tribute" cannot expect full compliance and only can hope for it. The latter gave the impetus to the transformation of "tribute - bribe" into "official" ("service", social) privileges, which according to the custom (tradition), should be granted to a person who occupies a certain social position in a sub-state society.

This allows drawing several conclusions:

- a prerequisite for corruption is the possibility of obtaining benefits due to one's social situation. The pre-corruption custom in the form of "tribute - gift - bribe" was not a socially harmful phenomenon, but on the contrary, was encouraged by the norms of morality, which stimulated further evolution of societies. In this regard, it was an element of the initial legal mechanism of redistribution of public goods;

- pre-corruption custom generates "official" ("formal", social) privileges, which according to the custom (tradition) should be provided to a person who occupies a certain social position in a state-owned society. 
At present, such a complex phenomenon as corruption has transformed itself into a threat to political stability, sustainable development of the state and its national security.

Taking into account the existing views on "corruption", we will try to consider a system of anti-corruption measures in public administration.

It is difficult to define corruption as it manifests itself in various forms. Thus, corruption (from the Latin corrumpere - to spoil) in a more broad sense is an unlawful activity, which consists in the use by officials of their rights and official capacities for personal enrichment; graft and corruption of public and political figures. Any person who has the authority to distribute certain resources not belonging to him personally, at his own discretion (official, deputy, judge, law enforcement officer, administrator, examiner, doctor etc.) may be subject to corruption actions. The main stimulus for corruption is the possibility of obtaining economic profit, and the main deterrent factor is the risk of disclosure and punishment.

In accordance with the Law of Ukraine on Prevention of Corruption (Law of Ukraine on Prevention of Corruption, 2014), corruption should be understood as "the use by a person of a given authority or capabilities connected with it in order to obtain the improper advantage (benefit) or accept such a benefit or accept the promise/offer of such benefit for oneself or others or, accordingly, the promise/offer or provision of improper benefit to a person, or at his request to other natural or legal persons, in order to persuade the person to misuse his/her official powers or related capabilities."

According to the abovementioned definition, corruption in the narrow sense should be considered as any action aimed at achieving or obtaining any privileges or benefits through illegal conspiracies and bribes.

Corruption, therefore, is a negative phenomenon that poisons the social life of any state. The problem of corruption remains one of the most pressing for the system of state authorities. It hinders development, but at the same time, prevention and effective corruption counteraction measures are not usually based on an understanding of its origin. That is why it is necessary to develop specific technologies and methods that can reduce the manifestations of corruption and risks caused by its appearance.

The literature reveals several channels, through which corruption affects the medium and long-term growth potential of the country, namely (Terzi, 2015):

1. Domestic investment. Corruption not only reduces the return on investment but also creates uncertainty in the return on investments.

2. Corruption directly reduces foreign direct investment. This is particularly problematic as these processes are connected with the international transfer of know-how technology and management, and hence the pace of technological progress, which is the main source of long-term growth.
3. Competition. Corruption can weaken antimonopoly regulation, create barriers for new "players" or create other barriers that keep the privileges of the established firms. The weaker competition will affect productivity and innovation.

4. Entrepreneurship. As business reward diminishes, potential entrepreneurial talents can be targeted at alternative operators in the process of renting. The result will be a reduction in startups and innovations and, ultimately, a decrease in growth rates.

5. Quality of public expenditures. Corruption will affect the level and composition of public expenditures. First, it will increase the value of goods and services purchased by the public sector, reducing the funds needed for effective public use. Secondly, this will affect the cost structure, as resources will be directed to those areas where corruption can be more easily hidden.

Counteracting corruption as a specific activity in the field of public administration includes a system of measures including: political, legal, organizational, managerial, ideological, socio-psychological, and others.

The system of anti-corruption measures entails reducing the scale of corruption, changing the nature of its manifestations, and limiting its impact on social processes. This increases the risk for the corrupt officials. It also presupposes removing social preconditions for corruption, the causes and conditions of corruption; identifying, terminating, and investigating corruption; bringing to justice individuals who are guilty of committed corruption offenses; eliminating the consequences of corrupt acts.

The rule oflaw and legitimacy, as well as comprehensive implementation of legal and informational measures with the priority on prevention, should be the cornerstone of activities on combating corruption. The prevention activities, in particular, should include such principles as the inevitability of responsibility for the corruption offense, openness and transparency of the activities of state authorities and local selfgovernment bodies.

At present, the situation in the field of prevention and counteraction to corruption is characterized by several factors. On the one hand, there is a "new" agenda of state authorities against corruption, on the other - lack of concrete results. The problem is that the prevention process affects a fairly wide range of social relations, including the spheres of social life, where modern society does not have a direct influence. Often, economic reasons cause "corrupt behaviour". It is quite obvious that the state government can only partly affect economic processes in the country, especially in the context of the economic crisis. To a lesser degree, it is capable of influencing culture, the constituent part of which is the legal culture. Thus, the low level of legal culture, and more precisely legal nihilism, is the direct and immediate cause of corrupt behaviour. 
According to macroeconomic and political economy studies, corruption is the biggest obstacle to economic growth and development, which can jeopardize any transformation.

The main causes of corruption in Ukraine are:

- lack of political will to overcome corruption;

- lack of moral standards in the population (and as a consequence of officials), indifference;

- the imperfection of the judicial system;

- lack of transparency and inadequate level of accountability of state bodies;

- lack of effective punishment system for the bribes;

- convenience for many entrepreneurs and ordinary citizens to solve their problems with officials using bribes.

The consequences of the subsequent impact of corruption in Ukraine may be the following:

- the growth of socio-political tension (even the emergence of a revolutionary situation);

- further criminalization and spread of the shadow economy;

- disruption of the financial and economic system of the country;

- devaluation of moral values of the society;

- the decline in the positive international image of the country, deterioration of its political, economic, social, and legal positions on the world arena;

- loss of opportunities for the country to enter prestigious international organizations;

- international political and economic isolation etc.

The future development of the country is connected with the need to counteract corruption. This question is also important for social progress, normal life, and prevention of other challenges and threats. Ukraine's powerful potential in the economic, political, legal, and social spheres allows relying on the effective implementation of anticorruption policies and the effectiveness of anticorruption programs.

However, despite loud statements about the active counteraction to corruption, the bribery cases in the country are increasing. The average size of the bribe in 2016 was approximately 45,000 $\mathrm{UAH}$, in 2015 - 40,000 UAH, in 2014 - 30,000 UAH. The dollar rate increase is partly responsible for the increase in the sum (Transparency International Ukraine, 2016). Thus, according to courts' criminal proceedings on corruption charges and cases of administrative offenses, the following numbers are evident: 3261 people were prosecuted on charges associated with corrupt activities during 9 months of 2017. This number includes charges for corruption offenses -788 people, and for the administrative offenses connected with corruption -2473 persons. This is $40.2 \%$ of the total number of cases brought to court (8,109 cases) (Verhovniy Sud Ukrajiny, 2017).

This stipulates the necessity of introducing the most severe punishment and creating conditions for reducing the desire for taking bribes. For example, in a case of violation of the law on corruption, the guilty person should be deprived of the right to work in state institutions, lose all social privileges, including pension and social security, and pay large fines. In some countries, for example, bribery is equated with a violation of the Constitution and is considered treason.

International experience shows that all socioeconomic systems are not fully immune from corruption, only the amounts and manifestations change. Thus, corruption cannot be eliminated in any particular state or at some stage of historical development. The reduction of the level and the localization of corruption may be among the maximum positive achievements in this sphere, including the decrease in the level of corruption risk manifestations and their impact on various social processes. In Western countries, this process is called control over corruption (Ilienok, 2013). Eliminating bribery is absolutely impossible since the excessive implementation of control methods is very costly and countless efforts should be spent on complete elimination of corruption. In addition, hypertrophied strengthening of the fight against corruption deprives the administrative system of flexibility and the population of civil liberties. Comparing the losses from corruption with the costs of fighting corruption, one can strive to achieve a certain optimal level of corruption, which reflects the smallest aggregate losses.

\section{Economic and mathematical modelling of corruption situations and their susceptibility to countermeasures}

At the same time, the effectiveness and progress of the fight against corruption is assessed in reality considering efficient allocation of resources and taking into account economic efficiency; political priorities of the government; the effective work of the state authorities to achieve the intended results and the use of mechanisms that ensure responsibility for the achieved results.

We believe that the most effective means of combating corruption is to create a competitive environment "economic benefits - the risk of punishment". This should reduce the interest of officials in obtaining bribes since their size ceases to compensate for the risk of detention and disclosure.

This can be proved using the economic-mathematical model of maximizing the bribe, which takes into account the limitations regarding the possibility of offering and agreeing to receive a bribe:

$$
G=V-P-K \text {, }
$$

where $V$ - is the size of a bribe that an official can receive, $P$ - the expected amount of damage from the punishment of an official (for example, in the case of a court order to impose an arrest on property or impose a fine); $K$ - the costs of control activities (for example, public control and internal audit). The size of a bribe $V$ can be represented by formula (2): 


$$
V=\gamma \cdot v \cdot D,
$$

where $v$ - the size of the bribe (part of the revenue from the project, administrative service etc. which the official demands); $D$ - revenue from the implementation of all projects, administrative services etc., which are coordinated by an official; $v \cdot D$ - potential bribe revenue of an official;

$$
\gamma=\frac{v_{0}-v}{v_{0}}-\text { the probability of a person's consent to }
$$
give a bribe $(0<\gamma \leq 1)$;

$v_{0}$ - the maximum amount of the bribe, which the person agrees to give $\left(0<v_{0} \leq 1\right)$.

By combining all variables, we receive the profit model of the corrupt official:

$$
G=v \cdot D \cdot \frac{v_{0}-v}{v_{0}}-P(v)-K(v)
$$

The extremum is used to determine the maximum possible profit of the official (the zero derivative $G^{\prime}=0$ ):

$$
G^{\prime}=D \cdot \frac{v_{0}-2 v}{v_{0}}-P^{\prime}(v)-K^{\prime}(v)=0
$$

In such a way, the function has an extremum when:

$v=\frac{v_{0}}{2}\left(1-\frac{P^{\prime}(v)+K^{\prime}(v)}{D}\right)$

Let's consider possible cases:

1. If the fine for receiving a bribe and the cost of control actions does not depend on the size of the bribe $\left(P^{\prime}=0, K^{\prime}=0\right)$, then the maximum income from bribes is received by an official on the following condition:

$$
v_{\max }=\frac{v_{0}}{2} \text {. }
$$

Let's check if it is a maximum or a minimum of the function by finding a second derivative:

$$
G^{\prime \prime}=D \cdot\left(1-\frac{2}{v_{0}}\right)
$$

If $0<v_{0} \leq 1$, then $G^{\prime \prime}<0$, accordingly, this shows that we received the value of the part of the bribe when the function of income is maximized.

The result can be interpreted as follows: an official will receive maximum bribe if it forces to give half of the maximum possible bribe size ("to share equally"). In this case, the maximum income of the official equals to (8):

$$
G_{\max }=\frac{v_{0}}{4} \cdot D
$$

Trying to get a bigger amount of bribe will reduce the probability of the consent to a larger bribe, and if to take less - the total amount of the received bribes decreases.

2) The second case is more interesting and complicated.

If the sum of the marginal expenses from the punishment (court orders based on the results of the revealed corruption manifestations by the controlling bodies) is potentially more possible than the bribe revenue from the project implementation, administrative service etc. received by an official, meaning $P^{\prime}+K^{\prime} \geq D$, than

$$
v=\frac{v_{0}}{2}\left(1-\frac{P^{\prime}+K^{\prime}}{D}\right) \leq 0,
$$

It means that there is no such bribe amount that will allow an official to maximize one's income.

If $P^{\prime}+K^{\prime}<D$, then the maximum value of $G$ (the revenue of the official) exists when the size of the bribe has certain value $v<\frac{v_{0}}{2}$ reduced to the multiplier $\left(1-\frac{P^{\prime}+K^{\prime}}{D}\right)$.

Let's check if it is a maximum or a minimum of the function. In order to do this, one can find a second derivative.

$$
G^{\prime \prime}=D \cdot\left(1-\frac{2}{v_{0}}\right)-P^{\prime \prime}(v)-K^{\prime \prime}(v)
$$

If $0<v_{0} \leq 1$, then the first summand is negative. In this case, the form of the curves becomes important $-P(v)$ and $K(v)$.

If $P^{\prime \prime}>0$ and $K^{\prime \prime}>0$, then $G^{\prime \prime}<0$, and the function of bribe income of an official have maximum (Figure 1).

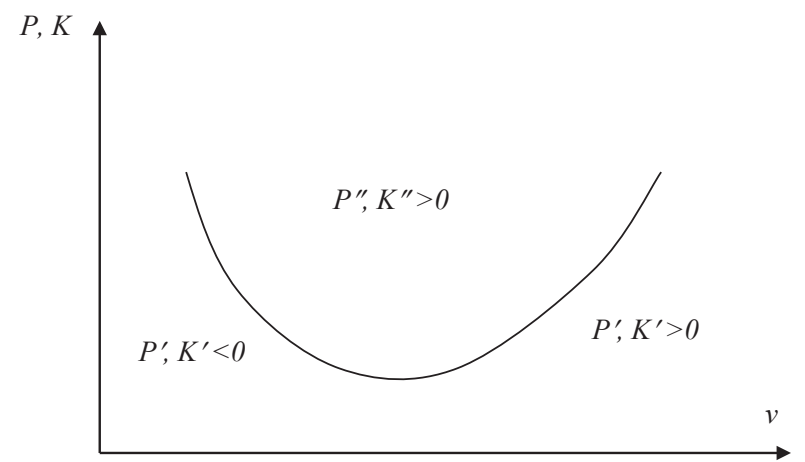

Figure 1. Dependence of the official's losses on the size of bribe when $P^{\prime \prime}>0$ and $K^{\prime \prime}>0$

It should be noted that the value of marginal costs $P^{\prime}<0$ and $K^{\prime}<0$ can indicate that the expected amount of damage from the punishment of an official $P$ and the cost of control actions $K$ decrease with the increase in the size of the bribe, which should not have occurred in real life, although it is possible from a mathematical point of view.

If $P^{\prime \prime}<0$ and $K^{\prime \prime}<0$, then $G^{\prime \prime}$ can have both positive and negative values (Figure 2 ).

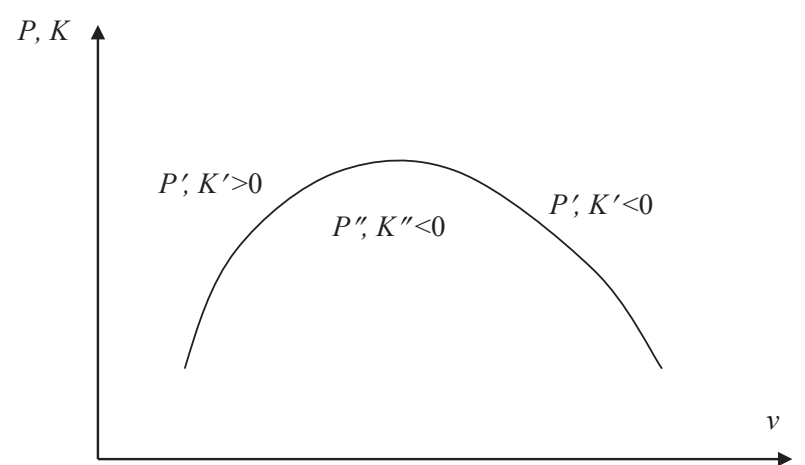

Figure 2. Dependence of the official's losses on the size of bribe providing that $P^{\prime \prime}<0$ and $K^{\prime \prime}<0$

$$
\text { If } P^{\prime \prime}(v)+K^{\prime \prime}(v)>D \cdot\left(1-\frac{2}{v_{0}}\right) \text {, then } G^{\prime \prime}<0 \text {, and again }
$$
there is an opportunity to maximize profits (Figure 3 ). 
Otherwise, if $P^{\prime \prime}(v)+K^{\prime \prime}(v)<D \cdot\left(1-\frac{2}{v_{0}}\right)$, then $G^{\prime \prime}>0$. It means that the function will have a minimum value, which indicates that it is impossible to maximize profits.

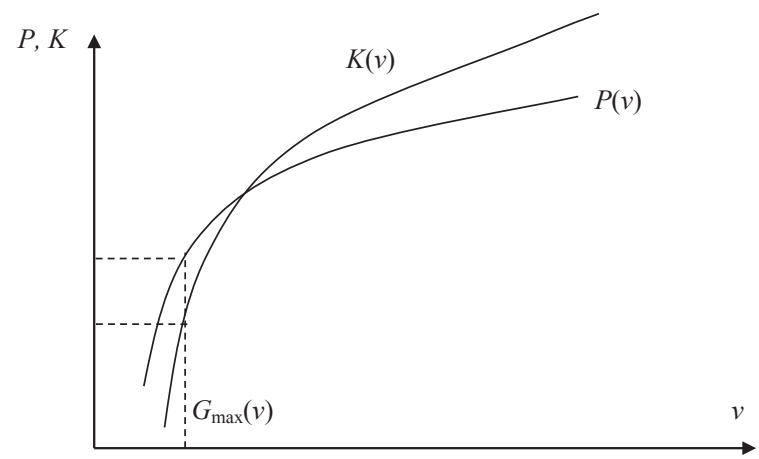

Figure 3. Determination of the profit of an official $G_{\max }$ providing that $P^{\prime}>0$ and $K^{\prime}>0$

The analysis shows that the problem of corruption can be resolved only with the introduction of comprehensive administrative (coercive) measures, which often have restrictive and repressive character. In the first place, they provide for extremely stringent control over the actions and incomes of officials and a high degree of fines and penalties depending on the size of the bribe.

This is quite evident from the geometric meaning of the derivative: the value of the derivative at the point is tangent to the angle of inclination of the tangent at this point. Accordingly, the greater the value of the possible revenue from the implementation of projects (the provision of administrative services), the greater should be the value of the tangent, and even more so the angle of inclination (Figure 4).

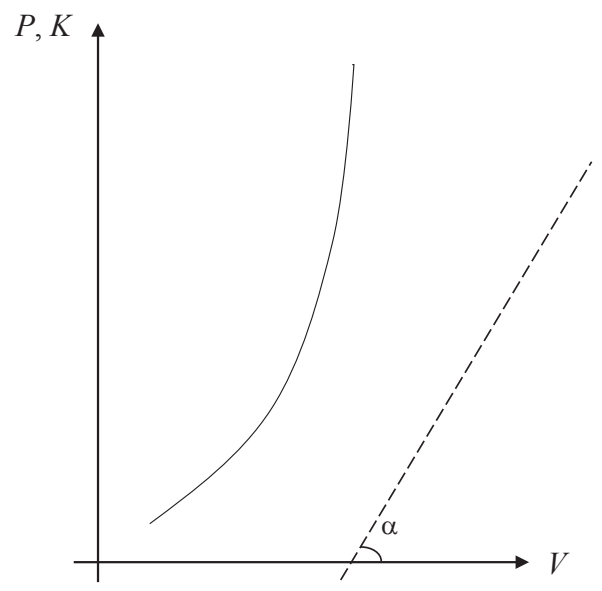

Figure 4. The geometric sense of determining the size of loss of an official

In addition to strengthening the control-regulatory function and "punitive" influence as an appropriate action of the state to the committed illegal actions by an official, political will of the authorities is required to fight corruption. The authorities should direct their efforts to the comprehensive implementation of the provisions of anti-corruption legislation and the practical application of technologies and methods of corruption counteraction and bribery.

According to the World Bank expert P. LandellMills (2013), anti-corruption legislation is formed by laws on combating corruption, extortion, and bribery; on the financing of political parties, as well as laws aimed at curbing corruption, in particular: on conflict of interests; introduction of free access of citizens to public information; on guaranteeing the protection from criminal prosecution of people who report cases of corruption (Landell-Mills, 2013).

The technologies of fighting corruption and bribery may be grouped in accordance with their spheres as follows:

- political technologies for combating corruption aimed at ensuring transparency of the decision-making by state bodies of all levels and bodies of local selfgovernment;

- ideological technologies for combating corruption - aimed at legal education and awareness creation for the society to be aware of the damage resulted from corruption, the recognition by the state and society of the fact that corruption is a threat to national security; - legal technologies for combating corruption - work with current legislation to bring it in line with the norms that form the anticorruption policy;

- organizational and technical technologies of combating corruption - aimed at improving the material provision of civil servants; implementation of systemic and well-considered personnel policy;

- institutional anti-corruption technologies - aimed at creating an effective institutional system for combating corruption and ensuring effective institutional counteraction, serving as the organizational basis for a holistic mechanism for ensuring economic law and order and maintaining economic and criminological security;

- socio-economic technologies of combating corruption - aimed at reducing cash circulation, expansion of modern electronic means of calculating the implementation of modern forms of reporting, which facilitate control over the movement of funds and complicate the possibility of giving bribes in cash; commercialization of a part of social (including communal) services; delegation of solving social tasks to civil society institutions; bringing together the real and official economy of various sectors and social institutions.

Thus, in order to overcome corruption, it is not enough to develop the economy and create anticorruption institutions. It is also necessary to promote the political will of the authorities, the efforts of which are aimed at the integrated implementation of technologies and methods of combating corruption and bribery.

Firstly, it is necessary to implement technological advances in order to reduce the number of personal contacts between citizens and government officials. 
This will help to increase transparency standards and simplify the task of ensuring effective monitoring of the quality of the provision of administrative services. It should be noted that the use of state-of-the-art technology for state anti-corruption policy will increase the overall efficiency of public administration.

However, it should be borne in mind that technological development requires the involvement of more talented and competent performers, linking the use of technological advances with the involvement of new personnel (Piketty, 2014).

\section{Discussion}

The literature shows two opposing views on the use of the methods of combating corruption. Proponents of the first position (Haraschuk, 2010; Melnyk, 2004; Nevmerzhytskyj, 2008) argue that the fight against corruption is necessary first and foremost through the implementation of economic and social reforms, that is to create conditions under which individuals who are potentially corrupt refrain from committing acts because they are more interested not to commit an illegal act than to commit it. The amount of the benefits they can receive as the result of the illegal activity is much less than they receive from a state for carrying out their assigned tasks. Supporters of such opinion believe that main negative factors are the low standard of living of civil servants and persons who are authorized to perform state functions; high prices for goods and services; destructive tax policy of the state, which makes it easier for a manufacturer to "buy" a civil servant rather than pay taxes etc. A somewhat similar opinion is expressed by Paskhaver (2014). He notes that the successful fight against systemic corruption in Ukraine involves initiating the implementation of fundamental economic and political measures and then deploying the whole arsenal of anticorruption technical means. The reciprocal sequence of actions is not only ineffective but also socially and politically dangerous (Paskhaver, 2014).

However, it is highly necessary to stop further spread of corruption in the country as the degree of corruption of the state apparatus threatens the existence of a democratic system. Therefore, the administrative methods should be used to detect bribery and ensure the inevitability of punishment for committing a corrupt act. This may stop the growth of corruption.

\section{Conclusions}

The systematization of corruption problems with state authorities and economic-mathematical modelling of the corruption situations proves the following: under the current conditions in Ukraine, the most optimal means to combat corruption should have a focus on the formation of competition based approach "economic benefit - the risk of punishment". It should contribute to reducing the interest of officials in obtaining a bribe and destroy the propensity to commit corruption. This, accordingly, stipulates an increase in the control-regulatory function and "punitive" influence as an appropriate action of the state and its bodies on committing unlawful actions by officials. However, "punitive" measures, even the hardest ones, do not affect the underlying causes of corruption as a negative social phenomenon which lie deep in the minds of Ukrainians and in the behavioural stereotypes. Therefore, one of the main goals in the fight against corruption should include the formation of an anticorruption model of behaviour in society, based on anticorruption legal awareness. Repressive and preventive methods of fighting corruption should be well-balanced.

Ukrainian new national anti-corruption model includes an institution where preventive and repressive functions are combined. Moreover, several specialized institutions that combine several preventive functions were created. However, there was no massive attack on corruption. The main reason for the ineffectiveness of these institutions, in most cases, might be their consulting and advisory nature, vagueness and duplication of powers, as well as the dependence of their work on the will of senior officials. Among other reasons, there might be the unwillingness of the country's leaders (the President, the Head of the Parliament, the Prime Minister) to overcome the oligarchic influence on the authorities. It is not an uncommon practice to use the quota principle and not the professional qualification while appointing to the executive positions in state bodies, law enforcement agencies, prosecutors' and customs' office. There is also a general unwillingness to check civil servants on "wealth-income" principle. Taking into consideration current situation in state authorities and local self-governments in Ukraine, despite the creation of numerous bodies to prevent corruption, it will be impossible to overcome systemic corruption in the near future without changing the political elite.

\section{References:}

Alforov, S. M. (2011). Administrative and legal activity on combating corruption in internal affairs bodies. Kharkiv: Zolota mylia.

Bratkovskyj, M. L. (2010). Trust as a mechanism for the implementation of public authority. Donetsk: "VIK".

Bublyk, M., Koval, V., Redkva, O. (2017). Analysis impact of the structural competition preconditions for ensuring economic security of the machine building complex. Marketing and management of innovations, 4, 229-240. doi: $10.21272 / \mathrm{mmi} .2017 .4-20$

Charron, N., Dahlström, C. \& Lapuente, V. (2016). Measuring meritocracy in the public sector in Europe: a new national and sub-national indicator. European journal on criminal policy and research, 22(3), 499-523. 
Flejchuk, M. I. (2008). Legalization of the economy and counteracting corruption in the system of economic security: theoretical foundations and strategic priorities in the conditions of globalization. Lviv: Ahill.

Haraschuk, V. M. (2010). Actual problems of fighting corruption in Ukraine. Kharkiv: Pravo.

Ilienok, T. V. (2013). Fight with corruption: international experience. Yurydychna nauka, 2, 71-77.

Kochanova, A. (2015). How does corruption affect economic growth? World Economic Forum. Retrieved from: https://www.weforum.org/agenda/2015/05/how-does-corruption-affect-economic-growth/

Kokhan, H. V. (2013). The phenomenon of political corruption: theoretical and methodological analysis. Kharkiv: NISD.

Landell-Mills, P. (2013). Citizens against corruption. Report from the front line. UK.: Partnership for Transparency Funding.

Law of Ukraine on prevention of corruption (2014). Verhovna Rada Ukrajiny. Retrieved from: http://zakon2.rada.gov.ua/laws/show/1700-18

Melnyk, M. I. (2004). Corruption - corrosion of power (social essence, tendencies and consequences, measures of counteraction). Kyiv: Yurydychna dumka.

Nevmerzhytskyj, Ye. V. (2008). Corruption in Ukraine: causes, consequences, mechanisms of counteraction. Kyiv: KNT.

Paskhaver, A. Y. (2014). Whom to be. Kyiv: Fond Poroshenka.

Piketty, T. (2014). Capital in the twenty-first century. The Belknap Press of Harvard University Press.

Rose-Ackerman, S. (2003). Corruption and the state: causes, consequences, reforms. Moscow: Logos.

Serohin, S. S. (2009). The social nature of corruption in public authorities. Derzhavne upravlinnia ta mistseve samovriaduvannia, 3(3), 202-207.

Terzi, A. (2015). Why fighting corruption in Italy matters for economic growth. World Economic Forum. Retrieved from: https://agenda.weforum.org/2015/05/why-fighting-corruption-in-italy-matters-for-economic-growth/

Transparency International Ukraine (2016). Fines for bribery are less than bribes themselves, and only one-fifth of the corruptionists are enjailed. Retrieved from: https://ti-ukraine.org/infographics/shtrafy-za-habarnytstvomenshi-za-habari-a-za-gratamy-lyshe-p-yata-chastyna-koruptsioneriv

Verhovniy Sud Ukrajiny (2017). The situation with fighting corruption in Ukraine during the first nine months of 2017. Retrieved from: http://www.scourt.gov.ua/clients/vsu/vsu.nsf 